\title{
UNDERSTANDING THE INFLUENCE OF SOCIOECONOMIC ENVIRONMENT ON PAEDIATRIC ANTIRETROVIRAL TREATMENT COVERAGE: TOWARDS CLOSING TREATMENT GAPS IN SUB-SAHARAN AFRICA
}

\author{
Daniel A. Adeyinka ${ }^{1}$, Meirion R. Evans ${ }^{2}$, Chamberline E. Ozigbu ${ }^{1}$, Hugo van Woerden ${ }^{2,3}$, Esther F. Adeyinka ${ }^{4}$, \\ Olanrewaju Oladimeji ${ }^{5,6}$, Chris Aimakhu ${ }^{7,8}$, Deborah Odoh ${ }^{1}$, Dick Chamla ${ }^{9}$ \\ ${ }^{1}$ National AIDS and STIs Control Programme, Department of Public Health, Federal Ministry of Health, Abuja, Nigeria \\ ${ }^{2}$ Institute of Primary Care and Public Health, Cardiff University, Cardiff, UK \\ ${ }^{3}$ Public Health Directorate, National Health Service, Highland, Inverness, UK \\ ${ }^{4}$ Department of Nursing, Obafemi Awolowo University, Ile-Ife, Osun State, Nigeria \\ ${ }^{5}$ Liverpool School of Tropical Medicine, Liverpool, UK \\ ${ }^{6}$ Centre for Community Health Care, Research and Development, Abuja, Nigeria \\ ${ }^{7}$ Department of Obstetrics and Gynaecology, University College Hospital, Ibadan, Nigeria \\ ${ }^{8}$ College of Medicine, University of Ibadan, Ibadan, Nigeria \\ ${ }^{9}$ Health Section, UNICEF, New York, USA
}

\section{SUMMARY}

Objective: Many sub-Saharan African countries have massively scaled-up their antiretroviral treatment (ART) programmes, but many national programmes still show large gaps in paediatric ART coverage making it challenging to reduce AIDS-related deaths among HIV-infected children. We sought to identify enablers of paediatric ART coverage in Africa by examining the relationship between paediatric ART coverage and socioeconomic parameters measured at the population level so as to accelerate reaching the 90-90-90 targets.

Methods: Ecological analyses of paediatric ART coverage and socioeconomic indicators were performed. The data were obtained from the United Nations agencies and Forum for a new World Governance reports for the 21 Global Plan priority countries in Africa with highest burden of motherto-child HIV transmission. Spearman's correlation and median regression were utilized to explore possible enablers of paediatric ART coverage.

Results: Factors associated with paediatric ART coverage included adult literacy $(r=0.6, p=0.004)$, effective governance $(r=0.6, p=0.003)$, virology testing by 2 months of age $(r=0.9, p=0.001)$, density of healthcare workers per 10,000 population $(r=0.6, p=0.007)$, and government expenditure on health $(r=0.5, p=0.046)$. The paediatric ART coverage had a significant inverse relationship with the national mother-to-child transmission (MTCT) rate $(r=-0.9, p<0.001)$ and gender inequality index $(r=-0.6, p=0.006)$. Paediatric ART coverage had no relationship with poverty and HIV stigma indices.

Conclusions: Low paediatric ART coverage continues to hamper progress towards eliminating AIDS-related deaths in HIV-infected children. Achieving this requires full commitment to a broad range of socioeconomic development goals.

Key words: HIV infections, sub-Saharan Africa, child, antiretroviral agents, delivery of health care, socioeconomic factors

Address for correspondence: D. A. Adeyinka, National AIDS/STIs Control Programme (NASCP), Department of Public Health, Federal Ministry of Health. Edo House, Ralph Sodeinde Street, Plot 75, Central Area, Abuja, Nigeria. E-mail: nascp_adeydan@yahoo.com

https://doi.org/10.21101/cejph.a4479

\section{INTRODUCTION}

It is remarkable that with innovative approaches and huge political commitment, the global epidemiological pattern of $\mathrm{HIV}$ is changing as the world struggles to achieve the goals of ending the AIDS epidemic by stopping HIV transmission and AIDS-related deaths by 2030 (1). However, it is evident that children living with HIV continue to experience persist- ent treatment gaps despite the scientific proof from published studies that have established the efficacy of early antiretroviral therapy (ART) initiation among children in clinical settings (2-4). Although the risk of HIV death among under-5 children is declining, paediatric HIV still contributes significantly to preventable child morbidity and mortality in the continent due to lack of diagnostic and treatment services for HIV-infected children $(5,6)$. In the face of serious political, economic and 
social challenges, paediatric AIDS which is an important factor in overall child survival continues to threaten future productivity and development in Africa. Sub-Saharan Africa bears 90\% of global burden of paediatric HIV infection but only 22\% of HIV positive children under 15 years received ART in 2013 (5). The causes of poor ART coverage among children are multiple, ranging from health system to programmatic level factors. These include fewer facilities providing early infant diagnosis (EID), paediatric antiretroviral (ARV) shortages especially fixed-dose combination, inadequate integration and linkages to health facilities and community structures, limited number of health care workers providing paediatric ART services, low retention in care, and stigma and discrimination $(7,8)$. Poor implementation of provider initiated testing and counselling (PITC) and weak decentralization of paediatric ART services also play a part (5-7). The programmatic consequences of these obstacles are massive, e.g. the inability of the system to identify HIV infected children and linking them into care. Although, several strategies have been developed and implemented to mitigate these bottlenecks and subsequent AIDS-related death in developed countries, paediatric HIV is also a concern because African migrants and ethnic minorities have higher HIV prevalence than the general population and are more likely to experience delayed HIV diagnosis and treatment. Oftentimes, they have specific legal impediments, cultural, linguistic barriers, and perceived stigma from their communities hence making it difficult in accessing HIV testing and care.

In 2010, the UNAIDS strategy was adopted to accelerate progress towards universal access to ART for people living with HIV (PLHIV) who are eligible for treatment by 2015 (9). However, the target could not be reached in 2015, as more than $60 \%$ of PLHIV did not have access to ART (10). To ensure treatment scale-up beyond 2015, a new 2020 target was set in 2013 to close the ART gaps (10). From the perspective of improving HIV treatment, care and support, a people-centred investment approach has been postulated by UNAIDS as a key component of HIV response, accelerating the target of helping $90 \%$ of all people living with HIV to know their HIV status, $90 \%$ of all people with diagnosed HIV infection to receive sustained ART, and 90\% of people receiving ART to have viral suppression (90-90-90) by the year 2020 (11). The critical enablers and developmental synergies that were hypothesized as the core building blocks of national AIDS responses included work on social exclusion, marginalization, criminalization, stigma, social protection, education, legal reform, gender equality, poverty reduction, gender-based violence, health systems, community systems, and employment practices. Evaluating the social and health factors which influence paediatric ART coverage in Africa has been an issue of great interest to policymakers in ascertaining the most important barriers and bottlenecks to programme success as little is known about the influence of socioeconomic and health characteristics on the effectiveness of national paediatric ART programmes in some African countries. We analysed socioeconomic correlations of national HIV response in various regions of the continent to increase our understanding of the relationship between paediatric ART coverage and socioeconomic factors in sub-Saharan Africa in a broader context of social determinants of health so as to accelerate achieving the UNAIDS 90-90-90 targets of paediatric ART.

\section{MATERIALS AND METHODS}

\section{Study Design and Data Sources}

This is an ecological study, which correlated country-level data on paediatric ART coverage (outcome variable) that were obtained from 2014 UNAIDS progress report on global AIDS epidemic plan (9) with a range of critical enablers for strategic investment of HIV response. A framework was developed by conceptualizing social determinants of paediatric ART coverage from programmatic experiences of the authors, published literature $(2-4,8)$ and reviewing the proposed critical enablers and developmental synergies from UNAIDS (11) (Fig. 1). There are different plausible pathways through which good leadership and governance could lead to improvement of economic indices. At the individual level, gender and economic inequalities may lead to women's economic dependence on men, resulting in reduced autonomous decisions as regards to care of their children (Fig. 1). Furthermore, at the national level, dimensions of leadership and governance play a key role in determining access to quality health care by strengthening health sector through government ownership and investment in paediatric HIV programmes.

The 21 Global Plan priority countries in Africa with highest burden of mother-to-child transmission (MTCT) were selected as they have different health system profiles, committed to global elimination of mother-to-child transmission (EMTCT) plan by 2015, but also are at different levels of prevention of mother-tochild transmission (PMTCT) programming and socioeconomic status. The representative countries were grouped into four regions based on their socio-political characteristics: Western Africa (Cote d'Ivoire, Ghana and Nigeria), Central Africa (Angola, Cameroon, Chad, and Congo), Eastern Africa (Burundi, Ethiopia, Kenya, and Uganda), and Southern Africa (Botswana, Lesotho, Malawi, Mozambique, Namibia, South Africa, Swaziland, Tanzania, Zambia, and Zimbabwe).

The outcome and predictor variables, data sources and year of data reporting were described in Table 1 . The outcome variable (paediatric ART coverage) was defined as the percentage of children ( $<15$ years) living with HIV receiving ART as derived from 2014 UNAIDS progress report on global AIDS epidemic plan. The other major data sources for predictor variables were 2014 World Health Statistics Report (12), 2011 Report of Forum for a new World Governance version 2.0 (13), 2011-2014 UNAIDS Reports of the PLHIV stigma index (14), World Bank (15), and 2014 UNDP Human Development Report (16). The predictor variables included leadership and governance (measured by governance index score), empowerment of women (measured by gender inequality index score), economic development (measured by adult literacy rate, Gini coefficient and unemployment rate), health system strengthening (measured by density of health workforce per 10,000 population, general government and external expenditure on health as percentage of total expenditure on health), service delivery (measured by MTCT rate, births attended by skilled health staff and infants born to women living with HIV receiving a virology test by 2 months of age - early infant diagnosis), and HIV stigma index (measured by PLHIV being denied health services including dental care due to their HIV status, exclusion from family activities and internal stigma causing shame). 


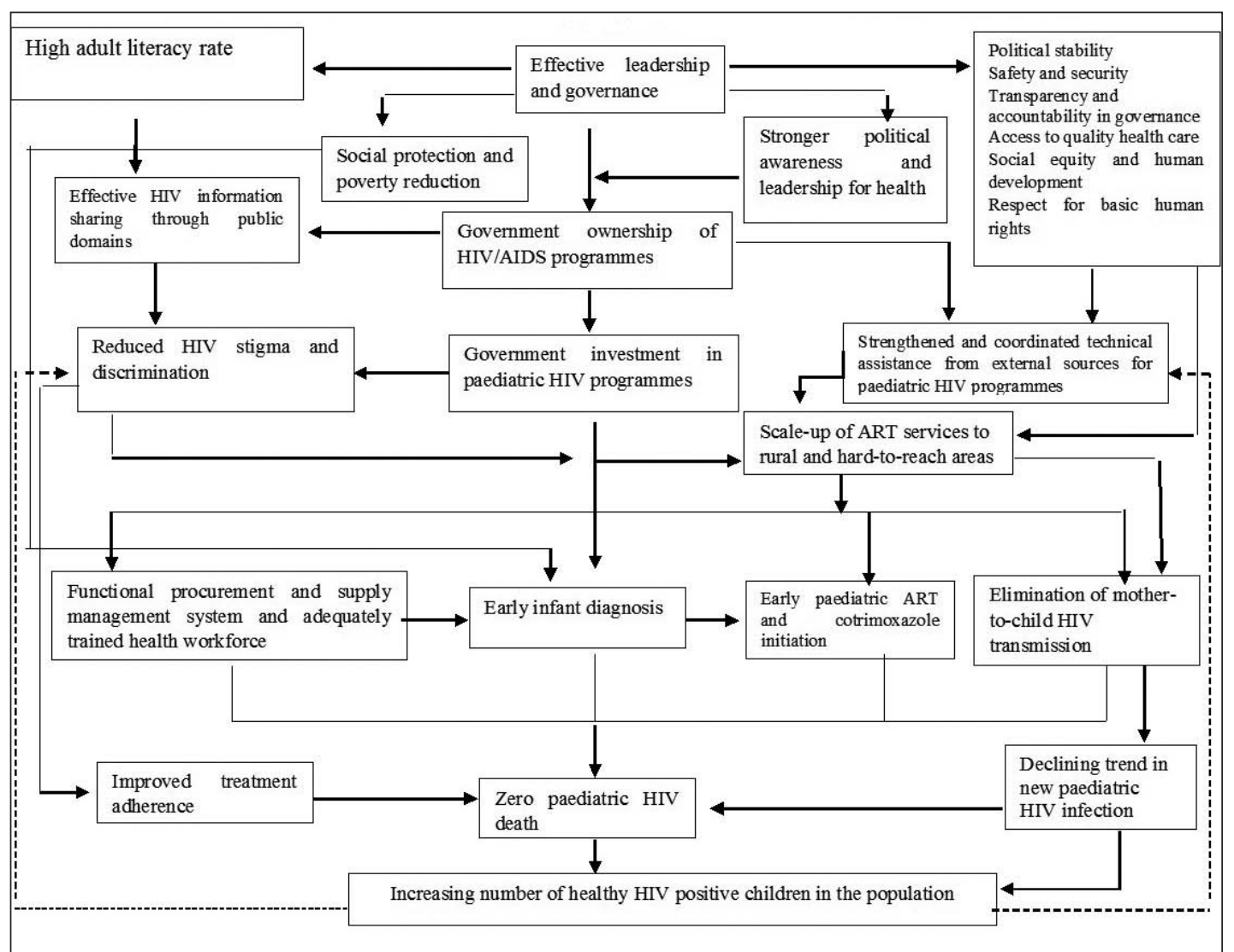

Fig. 1. Conceptual framework of relationship between socioeconomic indicators and paediatric ART coverage.

Governance index score ranged from 0 (which denotes ineffective governance) to 100 (which denotes a perfect score of effective governance). It reflects six dimensions of governance namely voice and accountability, political stability and lack of violence, government effectiveness, regulatory quality, rule of law, and control of corruption. We utilized governance index data from the report of 2011 Forum for a New World Governance for this analysis (16). Country-specific data on income Gini coefficient were obtained from the World Bank website. It measures deviation of the distribution of income among individuals or households within a country from a perfectly equal distribution. A value of 0 represents absolute equality and a value of 100 denotes absolute inequality. The gender inequality index is a composite measure reflecting gender disparity in three dimensions of reproductive health, empowerment and the labour market, where the lowest possible score is 0 (equality) and highest possible score is 1 (inequality).

\section{Ethical Statement}

Ethical approval was not required for this study as the data were obtained from secondary aggregate data sources in the public domain.

\section{Statistical Analysis}

The outcome and predictor data were extracted into Microsoft Excel and analysed with STATA v.12.0. A normal probability plot was used to visualize the pattern of each distribution. All the variables except governance index, gender inequality index, general government expenditure on health as percentage of total expenditure on health, externally funded expenditure on health as percentage of total expenditure on health, and births attended by skilled health staff were observed to be skewed. Hence, nonparametric methods were used to analyse the skewed variables. Mean and median were used for descriptive analysis of continuous variables and categorical variables were described by frequencies and percentages. Kruskal-Wallis test for equality-of-populations rank and one-way ANOVA were used to compare differences across the regions. We explored the pattern of relationships with scatter plots. For those cases where a linear relationship was observed, the strength of association between covariates was assessed by generating a Spearman's correlation matrix. Bivariate analyses using the outcome variable and each of the predictor variables were undertaken using median regression. We computed the least number of variables required with the lowest p-values for the multivariable analyses to give the best regression model. The $\beta$-coefficients were estimated based on the maximum likelihood method. A p-value of 0.05 was considered to be statistically significant.

\section{RESULTS}

Figure 2 describes the outcome variable (i.e. paediatric ART coverage) for each country. The median paediatric ART coverage was $16 \%$ (IQR: $11-31 \%$ ) with the highest and lowest coverage observed in Botswana (84\%) and Chad (5\%). As seen in Table 2 , there was significant difference in ART coverage for children $(p=0.004)$, being highest in Southern Africa (30\%, IQR: 22-45\%) and lowest in Central Africa (7\%, IQR: 5.5-11\%). 
Table 1. Description of variables and data sources

\begin{tabular}{|c|c|c|c|}
\hline Variable & Description & Source (reference) & Year of data reporting \\
\hline \multicolumn{4}{|l|}{ Outcome variable } \\
\hline Paediatric ART coverage & $\begin{array}{l}\text { Percentage of children living with HIV } \\
\text { (<15 years) receiving ART (children } \\
\text { receiving ART as a percent of all HIV } \\
\text { positive children) }\end{array}$ & $\begin{array}{l}2014 \text { UNAIDS Progress Report on Global } \\
\text { AIDS Epidemic Plan }\end{array}$ & 2013 \\
\hline \multicolumn{4}{|l|}{ Predictor variables } \\
\hline Index of Governance & $\begin{array}{l}\text { Percentage aggregated score for dimen- } \\
\text { sions of good governance: voice and } \\
\text { accountability, political stability and lack } \\
\text { of violence, government effectiveness, } \\
\text { regulatory quality, rule of law and control } \\
\text { of corruption; ranging from } 0 \text { (ineffective } \\
\text { governance) to } 100 \text { (perfect score of } \\
\text { effective governance). }\end{array}$ & $\begin{array}{l}\text { Report of Forum for a New World } \\
\text { Governance version } 2.0\end{array}$ & 2011 \\
\hline Gender Inequality Index score & $\begin{array}{l}\text { Measures of gender disparity in the } \\
3 \text { dimensions of reproductive health, } \\
\text { empowerment and labour market: the } \\
\text { lowest possible score is } 0 \text { (equality) and } \\
\text { highest possible score is } 1 \text { (inequality). }\end{array}$ & $\begin{array}{l}\text { United Nations Development Programme } \\
\text { (UNDP) Human Development Progress } \\
\text { Report } 2014\end{array}$ & 2013 \\
\hline Adult literacy rate & $\begin{array}{l}\text { Percentage of population ages } \geq 15 \text { who } \\
\text { can read and write a short simple state- } \\
\text { ment on their everyday life. }\end{array}$ & 2014 World Health Statistics Report & 2006-2012 \\
\hline Poverty Index & $\begin{array}{l}\text { Percentage of population living below } \\
\$ 1.25 \text { a day (extreme poverty) }\end{array}$ & World Bank Development Indicators 2013 & 2013 \\
\hline Gini coefficient & $\begin{array}{l}\text { Measured income inequality, where the } \\
\text { lowest possible value is zero and the } \\
\text { highest being one, when there is more } \\
\text { concentration of wealth. }\end{array}$ & World Bank Development Indicators 2013 & 2013 \\
\hline Unemployment rate & $\begin{array}{l}\text { Percentage of total labour force that is } \\
\text { without work but available for and cur- } \\
\text { rently seeking employment }\end{array}$ & World Bank Development Indicators 2013 & 2011-2014 \\
\hline HIV Stigma Index & $\begin{array}{l}\text { Measured by the percentages of PLHIV } \\
\text { who reported being denied health serv- } \\
\text { ices due to their HIV status, experienced } \\
\text { exclusion from family activities and felt } \\
\text { internal stigma causing shame in the } \\
\text { previous } 12 \text { months of data reporting. }\end{array}$ & UNAIDS PLHIV Stigma Index Report & 2011-2014 \\
\hline $\begin{array}{l}\text { Density of healthcare workers per } \\
10,000 \text { population }\end{array}$ & $\begin{array}{l}\text { Number of doctors, nurses and midwives } \\
\text { per } 10,000 \text { populations }\end{array}$ & 2014 World Health Statistics Report & 2006-2013 \\
\hline $\begin{array}{l}\text { General government expenditure } \\
\text { on health as percentage of total } \\
\text { expenditure on health }\end{array}$ & $\begin{array}{l}\text { Ratio of government expenditure on } \\
\text { health to total government expenditure } \\
\text { (expressed as \%) }\end{array}$ & 2014 World Health Statistics Report & 2011 \\
\hline $\begin{array}{l}\text { External resources for health as } \\
\text { percentage of total expenditure on } \\
\text { health }\end{array}$ & $\begin{array}{l}\text { Ratio of external resources for health to } \\
\text { total expenditure on health (expressed } \\
\text { as \%) }\end{array}$ & 2014 World Health Statistics Report & 2011 \\
\hline Mother to child HIV transmission rate & $\begin{array}{l}\text { Probability of perinatal or vertical trans- } \\
\text { mission of HIV infection which occurs } \\
\text { when HIV positive woman spread the } \\
\text { infection to her baby during pregnancy, } \\
\text { labour and delivery or breastfeeding. }\end{array}$ & $\begin{array}{l}2014 \text { UNAIDS Progress Report on Global } \\
\text { AIDS Epidemic Plan }\end{array}$ & 2013 \\
\hline $\begin{array}{l}\text { Infants born to women living with HIV } \\
\text { receiving virology test by } 2 \text { months } \\
\text { of age }\end{array}$ & $\begin{array}{l}\text { Percentage of HIV-exposed infants } \\
\text { receiving a virological HIV test within } 2 \\
\text { months of birth }\end{array}$ & $\begin{array}{l}2014 \text { UNAIDS Progress Report on Global } \\
\text { AIDS Epidemic Plan }\end{array}$ & 2013 \\
\hline Births attended by skilled health staff & $\begin{array}{l}\text { Percentage of deliveries conducted by } \\
\text { trained health personnel }\end{array}$ & $\begin{array}{l}2014 \text { UNAIDS Progress Report on Global } \\
\text { AIDS Epidemic Plan }\end{array}$ & 2013 \\
\hline
\end{tabular}




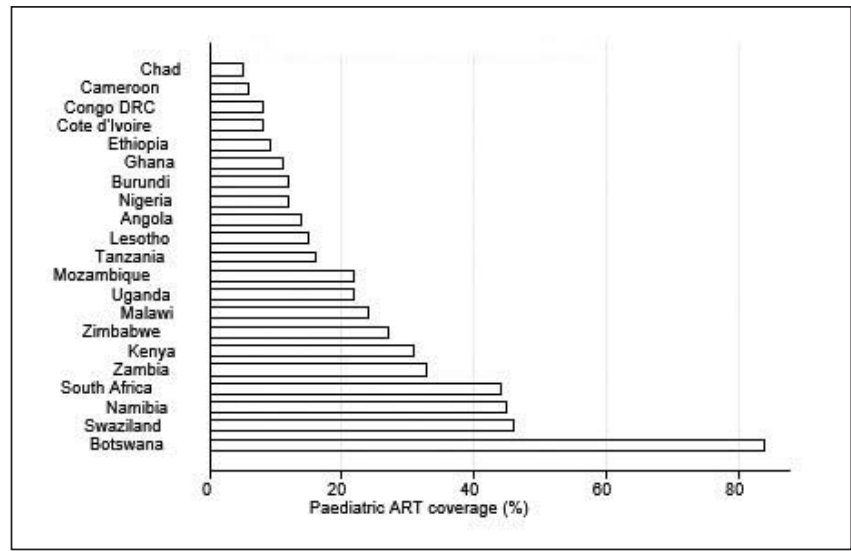

Fig. 2. Paediatric ART coverage.

\section{Leadership and Governance}

The mean governance index was $54 \%$ ( $S D=6.8 \%$ ), with little difference across the regions (Table 2). The scatter plot (Fig. 3a) indicates a clear linear relationship between paediatric ART coverage and governance index $(r=0.6, p=0.003)$.

\section{Empowerment of Women}

The mean gender inequality index score was high (0.6, $\mathrm{SD}=0.1$ ). The gender inequality score was lower among countries with a higher paediatric ART coverage $(r=-0.6, p=0.006)$.

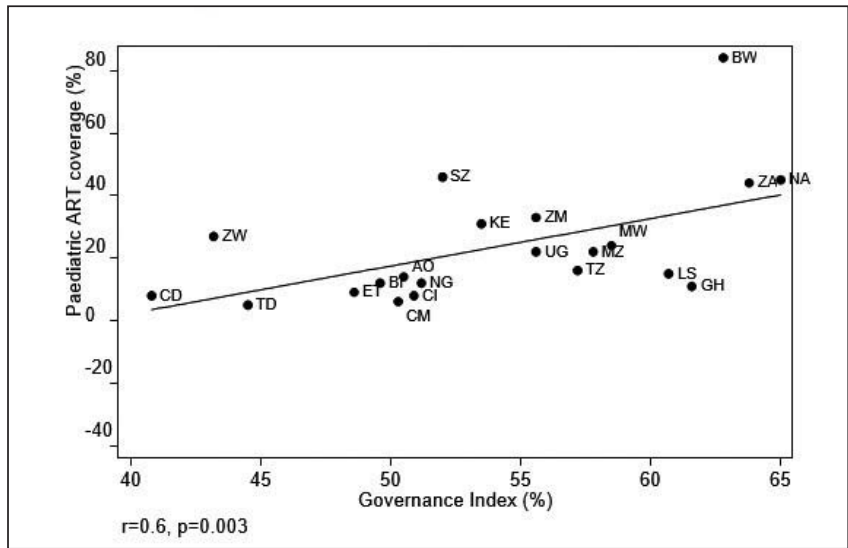

Fig. 3a Paediatric ART coverage and governance index.

Angola - AO, Botswana - BW, Burundi - BI, Cameroon - CM, Chad - TD, Congo DRC-CD Cote d'lvoire - Cl, Ethiopia - ET, Ghana - GH, Kenya - KE, Lesotho - LS , Malawi - MW, Mozambique - MZ, Namibia - NA, Nigeria - NG, South Africa - ZA, Swaziland - SZ, Tanzania - TZ, Uganda - UG, Zambia - ZM, Zimbabwe - ZW

Table 2. Descriptive analysis of continuous variables by regions

\begin{tabular}{|c|c|c|c|c|c|}
\hline Regions & Western Africa & Central Africa & Eastern Africa & Southern Africa & $\mathrm{p}$-value \\
\hline \multicolumn{6}{|l|}{ Outcome variable } \\
\hline Paediatric ART coverage, median \% (IQR) & $11(8-12)$ & $7(5.5-11)$ & $17(10.5-26.5)$ & $30(22-45)$ & 0.004 \\
\hline \multicolumn{6}{|l|}{ Predictor variables } \\
\hline Governance Index, mean \% (SD) & $54.6(6.1)$ & $46.5(4.7)$ & $51.8(3.3)$ & $57.7(6.4)$ & $0.03^{*}$ \\
\hline Gender Inequality Index, mean score (SD) & $0.6(0.1)$ & $0.7(0.04)$ & $0.5(0.02)$ & $0.6(0.1)$ & $0.0314^{*}$ \\
\hline Adult literacy rate, median \% (IQR) & $57(51-71)$ & $65.5(48-70.5)$ & $72.5(55.5-80)$ & $76(61-85)$ & 0.20 \\
\hline $\begin{array}{l}\text { Population living below } \$ 1.25 \text { a day, median } \\
\% \text { (IQR) }\end{array}$ & $35(28.6-62)$ & $40(32.1-65.6)$ & $40.6(37.3-62.4)$ & $43.5(23.5-60.7)$ & 0.9365 \\
\hline Gini coefficient, median \% (IQR) & $42.8(41.5-48.8)$ & 41.3(39.4-43.6) & $33.6(33.3-47.7)$ & $52(44.8-60.3)$ & 0.0851 \\
\hline Unemployment rate, median \% (IQR) & $4.6(4-7.5)$ & $6.9(5.4-7.5)$ & $6.3(4.8-8.1)$ & $15.1(7.6-22.5)$ & 0.1138 \\
\hline Denied health services, median \% (IQR) & 20 & 5 & $9(4.5-15)$ & $5.9(4.5-8)$ & 0.3048 \\
\hline $\begin{array}{l}\text { Experienced exclusion from family activities, } \\
\text { median (IQR) }\end{array}$ & 34.3 & 12.9 & $25.6(9.6-30)$ & $11.7(10.3-13.6)$ & 0.3476 \\
\hline $\begin{array}{l}\text { Felt internal stigma causing shame, median } \\
\text { (IQR) }\end{array}$ & 62.5 & 35.2 & $45.6(43.8-51.2)$ & $25.9(16.7-34.8)$ & 0.1222 \\
\hline $\begin{array}{l}\text { Density of healthcare workers per 10,000 } \\
\text { population, median (IQR) }\end{array}$ & $10.3(6.2-20.2)$ & $5.2(2.3-18.3)$ & $6.3(2.8-9.8)$ & $13.5(4.5-31.5)$ & 0.59 \\
\hline $\begin{array}{l}\text { General government expenditure on health } \\
\text { as percentage of total expenditure on health, } \\
\text { mean } \%(\mathrm{SD})\end{array}$ & $38.1(16.1)$ & 44.4 (15.1) & $44.4(16.2)$ & $59.4(13.6)$ & $0.12^{*}$ \\
\hline $\begin{array}{l}\text { External resources for health as percentage } \\
\text { of total expenditure on health, mean \% (SD) }\end{array}$ & $9.8(4.2)$ & $16.8(17.4)$ & $41.5(10.4)$ & $29.7(23)$ & $0.14^{\star}$ \\
\hline $\begin{array}{l}\text { Mother to Child HIV Transmission rate, } \\
\text { median \% (IQR) }\end{array}$ & $23(21-26)$ & $27(25-30.5)$ & $20.5(14.5-25)$ & $12.5(10-15)$ & 0.0035 \\
\hline $\begin{array}{l}\text { Infants born to women living with HIV receiv- } \\
\text { ing virology test by } 2 \text { months of age, median } \\
\% \text { (IQR) }\end{array}$ & $15(4-30)$ & $13.5(7-20.5)$ & $28.5(19-39)$ & $52.5(35-58)$ & 0.0158 \\
\hline $\begin{array}{l}\text { Births attended by skilled health staff, mean } \\
\% \text { (SD) }\end{array}$ & $55(15.4)$ & $53.5(24.4)$ & $46(16.8)$ & $68.1(16.2)$ & $0.2224^{*}$ \\
\hline
\end{tabular}

*One-way ANOVA was used while other associations were tested with Kruskal-Wallis equality-of-populations rank test. 


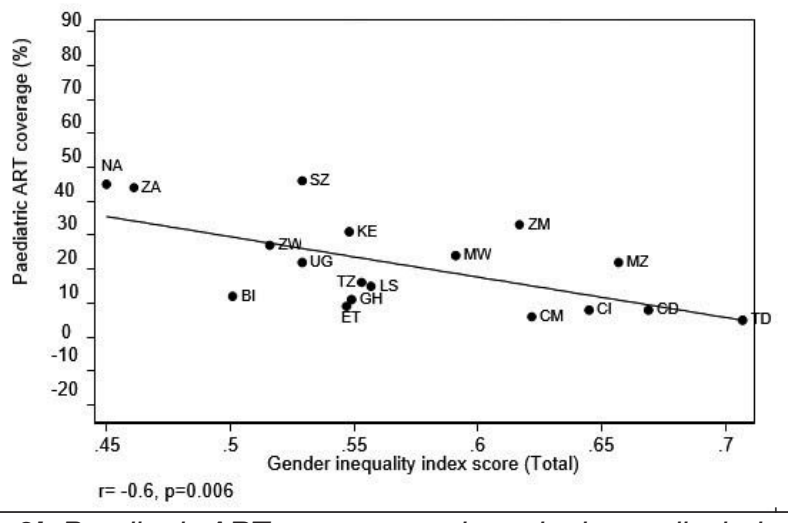

Fig. 3b Paediatric ART coverage and gender inequality index score.

Angola - AO, Botswana - BW, Burundi - BI, Cameroon - CM, Chad - TD, Congo DRC-CD, Cote d'Ivoire - Cl, Ethiopia - ET, Ghana - GH, Kenya - KE, Lesotho - LS, Malawi - MW, Mozambique - MZ, Namibia - NA, Nigeria - NG, South Africa - ZA, Swaziland - SZ, Tanzania - TZ, Uganda - UG, Zambia - ZM, Zimbabwe - ZW

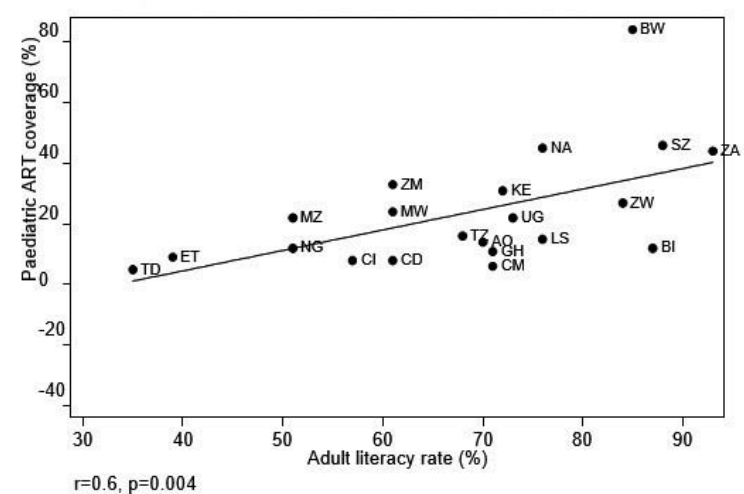

Fig. 3c Paediatric ART coverage and adult literacy rate.

Angola - AO, Botswana - BW, Burundi - BI, Cameroon - CM, Chad - TD, Congo DRC-CD, Cote d'Ivoire - Cl, Ethiopia - ET, Ghana - GH, Kenya - KE, Lesotho - LS, Malawi - MW, Mozambique - MZ, Namibia - NA, Nigeria - NG, South Africa - ZA Swaziland - SZ, Tanzania - TZ, Uganda - UG, Zambia - ZM, Zimbabwe - ZW

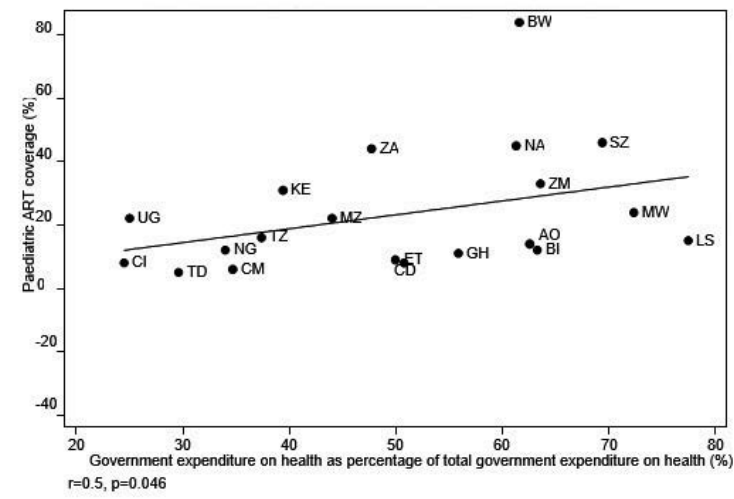

Fig. 3e Paediatric ART coverage and government expenditure on health.

Angola - AO, Botswana - BW, Burundi - BI, Cameroon - CM, Chad - TD, Congo DRC-CD, Cote d'Ivoire - Cl, Ethiopia - ET, Ghana - GH, Kenya - KE, Lesotho - LS, Malawi - MW, Mozambique - MZ, Namibia - NA, Nigeria - NG, South Africa - ZA Swaziland - SZ, Tanzania - TZ, Uganda - UG, Zambia - ZM, Zimbabwe - ZW

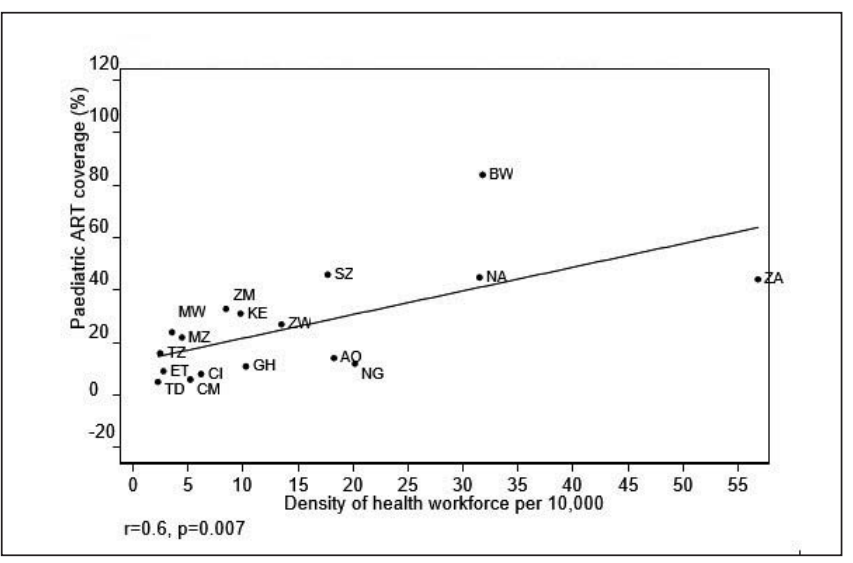

Fig. 3d Paediatric ART coverage and density of health workforce.

Angola - AO, Botswana - BW, Burundi - BI, Cameroon - CM, Chad - TD, Congo DRC-CD, Cote d'Ivoire - Cl, Ethiopia - ET, Ghana - GH, Kenya - KE, Lesotho - LS, Malawi - MW, Mozambique - MZ, Namibia - NA, Nigeria - NG, South Africa - ZA, Swaziland - SZ, Tanzania - TZ, Uganda - UG, Zambia - ZM, Zimbabwe - ZW

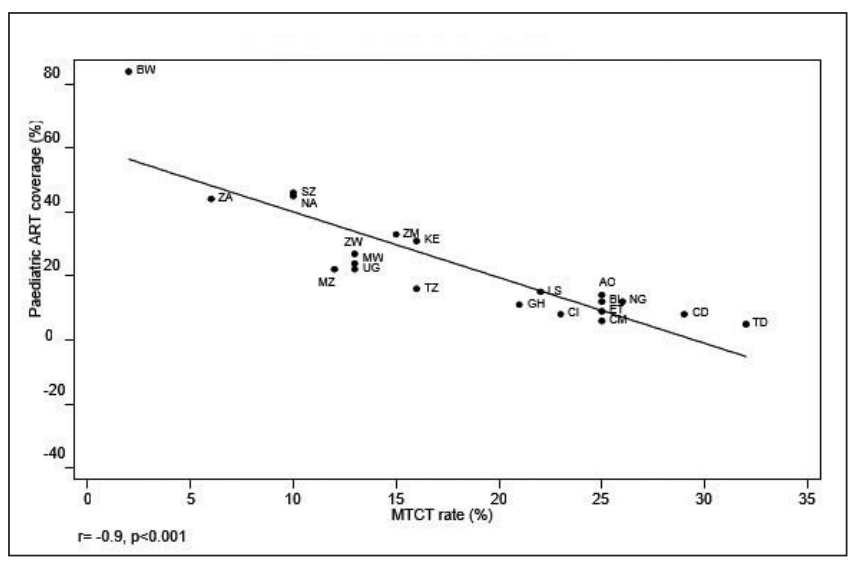

Fig. 3f Paediatric ART coverage and MTCT rate.

Angola - AO, Botswana - BW, Burundi - BI, Cameroon - CM, Chad - TD, Congo DRC-CD, Cote d'Ivoire - Cl, Ethiopia - ET, Ghana - GH, Kenya - KE, Lesotho - LS, Malawi - MW, Mozambique - MZ, Namibia - NA, Nigeria - NG, South Africa - ZA Swaziland - SZ, Tanzania - TZ, Uganda - UG, Zambia - ZM, Zimbabwe - ZW

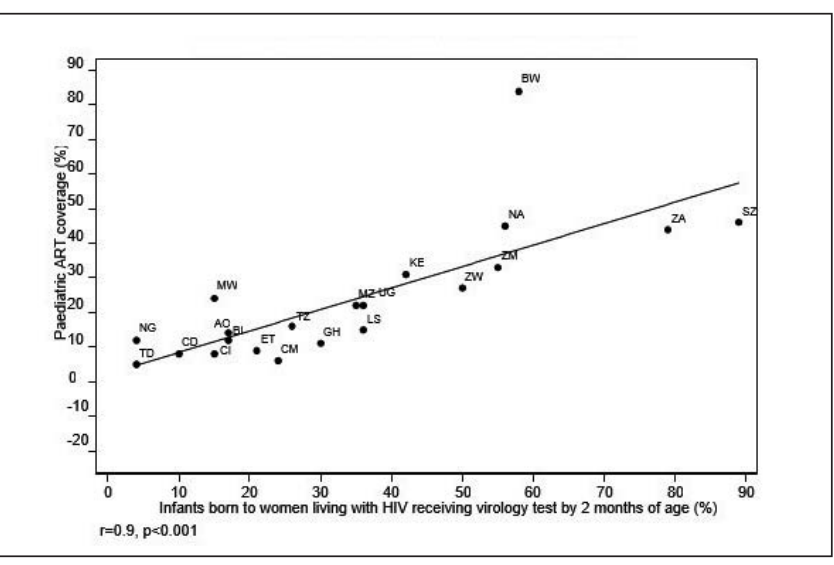

Fig. $3 g$ Paediatric ART coverage and infant diagnosis at 2 months.

Angola - AO, Botswana - BW, Burundi - BI, Cameroon - CM, Chad - TD, Congo DRC-CD, Cote d'Ivoire - Cl, Ethiopia - ET, Ghana - GH, Kenya - KE, Lesotho - LS, Malawi - MW, Mozambique - MZ, Namibia - NA, Nigeria - NG, South Africa - ZA, Swaziland - SZ, Tanzania - TZ, Uganda - UG, Zambia - ZM, Zimbabwe - ZW 


\section{Economic Development}

The lowest adult literacy rate was observed for Western Africa at 57\%, while Southern Africa had the highest rate at 76\%. The adult literacy rate ranged from 35\% (Chad) to 93\% (South Africa). There is evidence to suggest that countries with higher literacy rate had greater paediatric ART coverage $(r=0.6, p=0.004)$. Approximately 43\% (IQR: 32-61\%) of African population live below \$1.25 per day (extreme poverty). However, no relationship was observed between paediatric ART coverage and poverty index $(\mathrm{r}=-0.1, \mathrm{p}=0.610)$.

The Gini coefficient and unemployment rate were $44.2 \%$ (IQR: $39.8-51.5 \%)$ and 7.5\% (IQR: 5.4-13.3\%), respectively. The graphical distribution of the relationship between ART coverage in children in relation to Gini coefficient and unemployment suggests, counterintuitively, that ART coverage increases as income inequality $(r=0.7, p=0.001)$ and unemployment $(r=0.6$, $\mathrm{p}=0.004)$ increase.

\section{HIV Stigma Index}

Looking at HIV stigma and discrimination, 6.2\% (IQR: 4.6-8.9\%) of people living with HIV reported being denied health services including dental care because of their HIV status, $12.9 \%$ (IQR: 10.5-26.5\%) experienced exclusion from family activities and one-quarter felt internal stigma causing shame. However, no relationship was observed between paediatric ART coverage and HIV stigma index in the parameters that were studied.

\section{Health System Strengthening}

The density of health workforce (physician, nurses and midwives) was generally low, 9.8 (IQR: 4.5-18.3) per 10,000 population. This was highest in South Africa (56.8) and lowest in Chad (2.3). Countries with a high paediatric ART coverage had a significantly higher density of health workforce per 10,000 population $(r=0.6, p=0.007)$. Except for Mozambique, Tanzania and Uganda, general government expenditure on health as percentage of total expenditure on health was higher across the regions compared to external resources for health as percentage of total expenditure on health $(50.2 \%, \mathrm{SD}=16.1 \%$; and $26.5 \%$, SD $=20.2 \%$ ), respectively. Correlation coefficients indicated that increasing government expenditure on health was associated with a higher rate of paediatric ART coverage $(r=0.5, p=0.046)$. However, external expenditure on health appeared not to be related to paediatric ART coverage $(r=0.02$, $\mathrm{p}=0.93)$.

\section{Service Delivery}

The overall MTCT rate was 16\% (IQR: 13-25\%) and the proportion of infants born to women living with HIV receiving virology test by 2 months of age was 30\% (IQR: 17-50\%). The paediatric ART coverage correlated significantly with MTCT rate $(\mathrm{r}=-0.9, \mathrm{p}<0.001)$ and HIV-exposed infants receiving virology test by 2 months of age $(r=0.9, p<0.001)$. Over half $(58.8 \%, S D=$ $18.9 \%$ ) of births were attended by skilled health staff. Indeed, the percentage of deliveries by skilled birth attendants was somewhat related to ART coverage in children but the relationship was not statistically significant $(r=0.4, p=0.088)$.

\section{Multivariate Analysis}

In multivariate analysis, MTCT rate, governance index, unemployment rate, and percentage of infants born to women living with HIV receiving virology test by 2 months of age were included in the model. Only MTCT rate was significantly associated with paediatric ART coverage in the multivariate model $(\beta=-1.27$; 95\% CI: $-2.3,-0.24 ; \mathrm{p}=0.002)$.

\section{DISCUSSION}

Countries with higher paediatric ART coverage tended to have higher governance index, higher adult literacy rate, bigger health workforce, higher government expenditure on health, more uptake of EID, higher unemployment rate, and income inequality. Gender inequality and MTCT rate had an inverse relationship with paediatric ART coverage in the 21 African countries. Multivariate analysis indicated that the most significant factor was MTCT.

Health inequality has been widely reported as a major barrier of health service utilization globally and there is growing evidence that socio-economically disadvantaged populations include HIV exposed and infected children. Prior literature recognizes that inappropriate awareness of EMTCT and paediatric HIV services might be responsible for low detection and treatment coverage rates (5-7). So far, there is paucity of research in this area of paediatric HIV to provide a strong evidence base for its possible socioeconomic correlates hence making it difficult to formulate strategies for closing the existing treatment gaps. This study contributes to the limited literature in paediatric HIV care in the light of increasing understanding of the relationship between paediatric ART coverage and critical socioeconomic factors in sub-Saharan Africa. Also, this study reinforces that ensuring that no child is born with HIV through EMTCT strategies will allow for scalingup of linkages to paediatric HIV treatment in sub-Saharan Africa. Contrary to what was previously known, paediatric ART coverage is not associated with stigma. The lack of association might have resulted from an amplified HIV stigma-related awareness campaigns in the recent years leading to a more positive health seeking behaviour and friendly attitudes within communities towards PLHIV (17). Also, our results did not reflect poverty rate as a correlate but research elsewhere was inconclusive as relative poverty predicts health better than absolute poverty (18).

Our study shows that there is a link between good governance and successful implementation of HIV treatment services for children. Strong political leadership and commitment to HIV programmes are critical enablers necessary to accomplish the national paedatric ART targets and eradication of paediatric HIV (7). The governance index may be important because of its implications on programme ownership and sustainability, policy environment, human rights promotion, and health equity. In countries with low paediatric ART coverage, there is emerging evidence of gaps in coordination of the national response owing to the differing perspectives and practice resulting in a lack of ownership and clarity of process in implementing the HIV programmes. The relationship between general government expenditure on health as percentage of total expenditure on health and paediatric ART coverage had borderline statistical significance. Furthermore, inadequate domestic funding for health was observed which might be responsible for non-prioritization of paediatric HIV treatment 
services. However, there has been documented evidence that financial barriers have been impediment to HIV programmes (9, 19). Therefore, emphasis should be placed on making paediatric HIV a national priority and governments should consider having clearly defined budgets for paediatric ART.

Our analysis indicated that staff per 10,000 population varies from one country to the other. There were estimated 9.8 doctors, nurses and midwives per 10,000 population, but sub-Saharan Africa falls short of the minimum threshold of 23 per 10,000 population recommended by the WHO as necessary to deliver essential maternal and child health interventions. Large disparities in the distribution of health workforce across the regions compound the matter further, with Central and Eastern Africa being particularly under-resourced (5.2 and 6.3, respectively). For example, some countries notably Chad, Ethiopia and Tanzania have less than three healthcare staff per 10,000 population, whereas South Africa, Botswana and Namibia have 56.8, 31.8 and 31.5, respectively. These estimates did not take into account the type of services provided by the doctors, nurses and midwives. Urgent action is needed to address the causes of health worker shortages and in implementing clinical mentoring and task-shifting to best utilize human resources for health care by reallocating tasks within healthcare team.

We demonstrated that the proportion of children tested at 2 months was low (30\%). This is similar to findings from developing countries like Jamaica and Cambodia where much older children were enrolled into the programme (20, 21). In countries with high MTCT rate such as Chad, Congo DRC, Nigeria, Angola, and Burundi, it was observed that the proportion of infants tested for HIV by 2 months was low. This suggests that the large population of HIV exposed children might have overstrained their healthcare system making it difficult to test the children early. Moreover, we found a strong correlation between paediatric ART coverage and infants born to women living with HIV receiving virology test by 2 months of age. The gap between the number of EID and paediatric ART sites has been documented to have contributed to weak linkage of HIV infected children to treatment services (9). Identified HIV positive children are not being initiated early on ART because of shortages of HIV commodities and long turnaround time for dried blood spot result using PCR (9). From previous observational studies, the mean age at first DNA PCR for EID and ART initiation were 10 weeks and 5 years, respectively $(22,23)$. This might be attributed to health inequalities in different regions as paediatric ART programmes lag behind adult programmes (5). This observation is of key importance in generating demand for paediatric HIV services through provider initiated testing and counselling (PITC) and integration into the Maternal and Child Health services as some of the caregivers might not have adequate information on the availability of paediatric HIV services.

In spite of current global efforts in elimination of mother-tochild HIV transmission, it was observed that MTCT rate and gender inequality score were high (16\% and 0.6 , respectively), with unmet need of paediatric HIV services remaining inadequate in Africa. Among the countries, MTCT rate and gender inequality index score were consistently higher among countries with lower paediatric ART coverage. Importantly, Central Africa was observed to have the highest gender inequality index score (0.7) which might have been partly responsible for the highest MTCT rate observed there (27\%) and an associated low ART coverage for children (7\%). Likewise, this finding is consistent with the UNAIDS report that countries where gender inequality was not neglected showed improvement in uptake of ART services (11).

This study has identified education as an important association with paediatric ART coverage. Our findings indicated that adult literacy was positivity correlated with paediatric ART coverage. However, a major obstacle was the low level of education among adults especially in Western Africa (43\%) and Central Africa (34\%). This result corroborates the findings by Okomo et al. who identified that the caregivers were predominantly illiterate grand-parents with poor health-seeking behaviours (24). Also, Mondal and Shitan in their study have identified that being able to understand medical treatment is crucial for treatment adherence (25). Therefore, illiteracy can pose a long term barrier to accessing treatment and optimizing adherence especially in PLHIV. Our findings underscore the importance of promoting health literacy through the use of simplified information, education and communication (IEC) materials during community advocacy and awareness outreaches.

Comparable to other studies outside Africa, migrant populations which represent a significant proportion of reported HIV cases in high-income countries is attributed to epidemiological patterns in countries of origin such as high prevalence settings of sub-Saharan Africa. The identified barriers to migrants and ethnic minorities accessing HIV testing and care in France, Spain, United Kingdom, Canada, and the United States included stigmatization and discrimination by their community, implication on legal status, high levels of unemployment, poverty, low social status, and inequalities (26-31). Several studies have highlighted the need to remove socioeconomic barriers that deter African migrants from being tested for HIV and linked to HIV care (26-27).

A distinctive finding for which further research is needed is the result that suggested that paediatric ART coverage is greater in countries with higher unemployment rates and greater income inequality, whereas the opposite would be expected. This finding might have been due to residual confounding. This finding might also have been due to the ecological fallacy.

Ecological studies at population level are important when considering social risks that cannot be deduced from individual level data and can be used to develop policy and plan healthcare programmes by government. However, our findings require cautious interpretation because associations at both country and regional levels might not reflect associations at the individual level. As with all correlation studies, significant limitations exist with respect to causal inferences and are inherent in this study.

\section{CONCLUSION}

Low paediatric ART coverage in sub-Saharan Africa have continued to hamper satisfactory progress towards eliminating AIDS-related deaths among HIV-infected children. This study has provided evidence of inter-relationships between paediatric ART coverage and the socioeconomic environment. Ensuring the survival of HIV-infected children requires broader development planning processes and greater commitment from social, economic and political leadership.

\section{Conflict of Interests}

None declared 


\section{Authors' Contributions}

DAA and MRE conceptualized the idea. DAA, MRE, HvW and DC contributed to the study design. DAA collected the data and performed the statistical analysis. All authors interpreted results. DAA first drafted the manuscript. All authors made critical revision of the manuscript for important intellectual content. All authors read and approved the final manuscripts.

\section{REFERENCES}

1. Joint United Nations Programme on HIV and AIDS. AIDS by the numbers. UNAIDS; 2013.

2. Ciaranello AL, Chang Y, Margulis AV, Bernstein A, Bassett IV, Losina E, et al. Effectiveness of pediatric antiretroviral therapy in resource-limited settings: a systematic review and meta-analysis. Clin Infect Dis. 2009 Dec 15;49(12):1915-27.

3. Davies MA, Egger M, Keiser O, Boulle A. Paediatric antiretroviral treatment programmes in sub-Saharan Africa: a review of published clinical studies. Afr J AIDS Res. 2009 Oct;8(3):329-338.

4. Sutcliffe CG, van Dijk JH, Bolton C, Persaud D, Moss WJ. Effectiveness of antiretroviral therapy among HIV-infected children in sub-Saharan Africa. Lancet Infect Dis. 2008 Aug;8(8):477-89.

5. World Health Organization. Global update on the health sector response to HIV, 2014. Geneva: WHO; 2014.

6. African Union. Status report on maternal newborn and child health. Addis Ababa: African Union; 2012.

7. United Nations Children's Fund. Towards an AIDS-free generation, children and AIDS: sixth stocktaking report. New York: UNICEF; 2013.

8. Ubesie AC. Pediatric HIV/AIDS in sub-Saharan Africa: emerging issues and way forward. Afr Health Sci. 2012 Sep;12(3):297-304.

9. Joint United Nations Programme on HIV and AIDS. Progress report on the global plan towards the elimination of new HIV infections among children by 2015 and keeping their mothers alive. Geneva: UNAIDS; 2014.

10. Joint United Nations Programme on HIV and AIDS. 90-90-90: an ambitious treatment target to help end the AIDS epidemic. New York: UNAIDS; 2014.

11. Joint United Nations Programme on HIV and AIDS. HIV/AIDS: understanding and acting on critical enablers and development synergies for strategic investments. New York: UNAIDS; 2012.

12. World Health Organization. World Health Statistics 2014. Geneva: WHO; 2014.

13. World Governance Index (WGI): Why should world governance be evaluated and for what purpose? Forum for New World Governance Version 2.0 Report. Forum for New World Governance; 2011.

14. Joint United Nations Programme on HIV and AIDS. The people living with HIV stigma index [Internet]. UNAIDS; 2011-2014 [cited 2015 April 21]. Available from: http://www.stigmaindex.org.

15. World Bank. Indicators [Internet]. World Bank Group; 2013 [cited 2015 April 21]. Available from: http://data.worldbank.org/indicator.
16. United Nations Development Programme. Human Development Report. New York: UNDP; 2013.

17. Joint United Nations Programme on HIV and AIDS. HIV-related stigma, discrimination and human rights violations: case studies of successful programmes. Geneva: UNAIDS; 2005.

18. Wilkinson RG. The impact of inequality. Soc Res. 2006;73(2):711-32.

19. Resch S, Hong W, Michael KO, Gilbert K. Sustainability analysis of HIV/AIDS services in Nigeria. Bethesda, MD: United States Agency for International Development; 2009.

20. Pierre RB, Steel-Duncan JC, Evans-Gilbert T, Rodriguez B, Moore J, et al. Effectiveness of antiretroviral therapy in treating paediatric HIV/ AIDS in Jamaica. West Indian Med J. 2008 Jun;57(3):223-30.

21. Janssens B, Raleigh B, Soeung S, Akao K, Te V, Gupta J, Vun MC, et al. Effectiveness of highly active antiretroviral therapy in HIV-positive children: evaluation at 12 months in a routine program in Cambodia. Pediatrics. 2007 Nov;120(5):e1134-40.

22. U.S. President's Emergency Plan for AIDS Relief. Raid assessment of paediatric HIV treatment in Nigeria. USAID/PEPFAR; 2013.

23. McNairy ML, Lamb MR, Carter RJ, Fayorsey R, Tene G, Mutabazi V, et al.; Identifying Optimal Models of HIV Care and Treatment in Sub-Saharan Africa Consortium. Retention of HIV-infected children on antiretroviral treatment in HIV care and treatment programs in Kenya, Mozambique, Rwanda, and Tanzania. J Acquir Immune Defic Syndr. 2013 Mar 1;62(3):e70-81.

24. Okomo U, Togun T, Oko F, Peterson K, Townend J, Peterson I, et al. Treatment outcomes among HIV-1 and HIV-2 infected children initiating antiretroviral therapy in a concentrated low prevalence setting in West Africa. BMC Pediatr. 2012 Jul 8;12:95. doi: 10.1186/1471-2431-12-95.

25. Mondal MN, Shitan M. Factors affecting the HIV/AIDS epidemic: an ecological analysis of global data. Afr Health Sci. 2013 Jun;13(2):301-10.

26. Alvarez-del Arco D, Monge S, Azcoaga A, Rio I, Hernando V, Gonzalez C, et al. HIV testing and counselling for migrant populations living in high-income countries: a systematic review. Eur J Public Health. 2013 Dec;23(6):1039-45.

27. Fakoya I, Reynolds R, Caswell G, Shiripinda I. Barriers to HIV testing for migrant black Africans in Western Europe. HIV Med. 2008 Jul;9 Suppl 2:23-5.

28. Prost A, Elford J, Imrie J, Petticrew M, Hart GJ. Social, behavioural, and intervention research among people of Sub-Saharan African origin living with HIV in the UK and Europe: literature review and recommendations for intervention. AIDS Behav. 2008 Mar;12(2):170-94.

29. Pérez-Molina JA, López-Vélez R, Navarro M, Pérez-Elías MJ, Moreno S. Clinicoepidemiological characteristics of HIV-infected immigrants attended at a tropical medicine referral unit. J Travel Med. 2009 JulAug;16(4):248-52.

30. Tariq S, Edwards SG, Nalabanda A, Ward H, Allen E, Fenton K, et al. Sexual health services for South Asians in London, UK: a case-control study. Int J STD AIDS. 2007 Aug;18(8):563-4.

31. Mitra D, Jacobsen MJ, O'Connor A, Pottie K, Tugwell P. Assessment of the decision support needs of women from HIV endemic countries regarding voluntary HIV testing in Canada. Patient Educ Couns. 2006 Nov;63(3):292-300.

Received June 29, 2015

Accepted in revised form April 28, 2016 